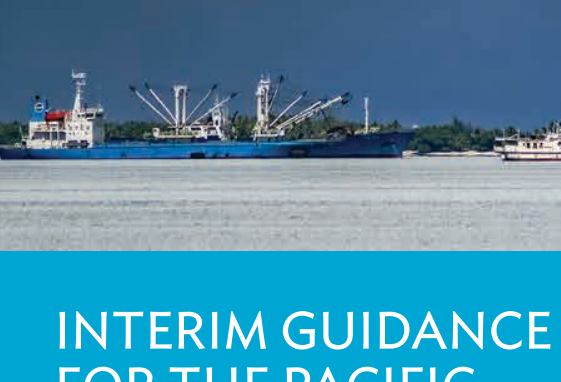 FOR THE PACIFIC
}

\section{Accounting for Changes in Extreme Daily Rainfall Intensity in Pacific Island Countries}

\section{Objective}

This interim guidance focuses on accounting for projected changes to extreme daily rainfall intensity in Pacific island countries when conducting feasibility studies, climate risk and adaptation assessments, and infrastructure design.

The advice and information provided here are based on the best available data and scientific understanding for the Pacific region. It is acknowledged that there are limitations associated with existing data and that significant knowledge gaps and uncertainties in the science remain (e.g., the role of natural climate variability and large-scale ocean-atmosphere circulation patterns, the influence of convective storm dynamics and atmospheric stratification, and the impacts of climate change on cloud microphysics and turbulence within clouds). Research is underway to address these issues. However, advice on accounting for changes in extreme rainfall intensity in the Pacific is required now.

In this interim guidance, examples are presented from two locations where observed data were available. But due to the small sample size, these examples should be viewed as illustrative rather than definitive. In due course, more extensive analysis of data across the Pacific will be undertaken and is expected to confirm that, as indicated by the two worked examples (and anecdotal evidence from across the Pacific), extreme rainfall intensity has increased with higher air temperatures. In the meantime, practitioners should be mindful of the need to apply a more precautionary approach (as laid out below).

\section{ANTHONY KIEM}

Hydroclimatologist

Centre for Water, Climate and Land

College of Engineering, Science and Environment

The University of Newcastle, Australia

E-mail:Anthony.Kiem@newcastle.edu.au

Web: http://www.newcastle.edu.au/ profile/anthony-kiem

\section{ANDREW MAGEE \\ Climate Change Scientist \\ Centre for Water, Climate and Land \\ College of Engineering, Science and Environment \\ The University of Newcastle, Australia \\ E-mail:andrew.magee@newcastle.edu.au Web: http://www.newcastle.edu.au/ profile/andrew-magee}




\section{Background}

The projected impacts of anthropogenic climate change on extreme rainfall intensity have been approximated previously using the Clausius-Clapeyron rate of 5\%-6.5\% increase per ${ }^{\circ} \mathrm{C}$ of global warming (Guerreiro et al. 2018; Ball et al. 2019). The presumption behind the Clausius-Clapeyron relationship is that during extreme precipitation events, if all other factors affecting precipitation remain equal, precipitation will be proportional to the amount of water held in the atmosphere (Ivancic and Shaw 2016). The maximum amount of water held in the atmosphere is determined by air temperature.

However, it has recently been demonstrated, that for many parts of the world, especially tropical regions (i.e., north of $23^{\circ} \mathrm{S}$ and south of $23^{\circ} \mathrm{N}$ ), the impacts of anthropogenic climate change could increase extreme sub-daily rainfall intensity by a rate 1.5-3 times greater than the increases expected based on the Clausius-Clapeyron rate (e.g., Singleton and Toumi 2013; Westra et al. 2014; Guerreiro et al. 2018; Fowler et al. 2021). This is referred to as Super-Clausius-Clapeyron (Super-CC) scaling.
Risks related to extreme rainfall are already high for many Pacific island countries and increases in extreme rainfall intensity will have significant economic, environmental, and social impacts. Therefore, it is necessary to

- evaluate how extreme rainfall intensity in the Pacific has changed over the last few decades,

- establish whether changes to extreme rainfall intensity in the Pacific over the last few decades are consistent with the Clausius-Clapeyron rate of $5 \%-6.5 \%$ increase per ${ }^{\circ} \mathrm{C}$ of global warming, and

- develop a method for quantifying the expected increase in extreme rainfall intensity in the Pacific when Super-CC scaling is applied.

It is important to acknowledge that, due to the current lack of sub-daily data in the Pacific, the focus of this guidance is on daily rainfall extremes. However, changes to sub-daily rainfall extremes are also important and are likely to be different to changes in daily rainfall extremes. Ongoing work is focused on identifying suitable sources of sub-daily data and assessing how sub-daily rainfall extremes have changed over the last few decades (Lewis et al. 2019; Li et al. 2020).

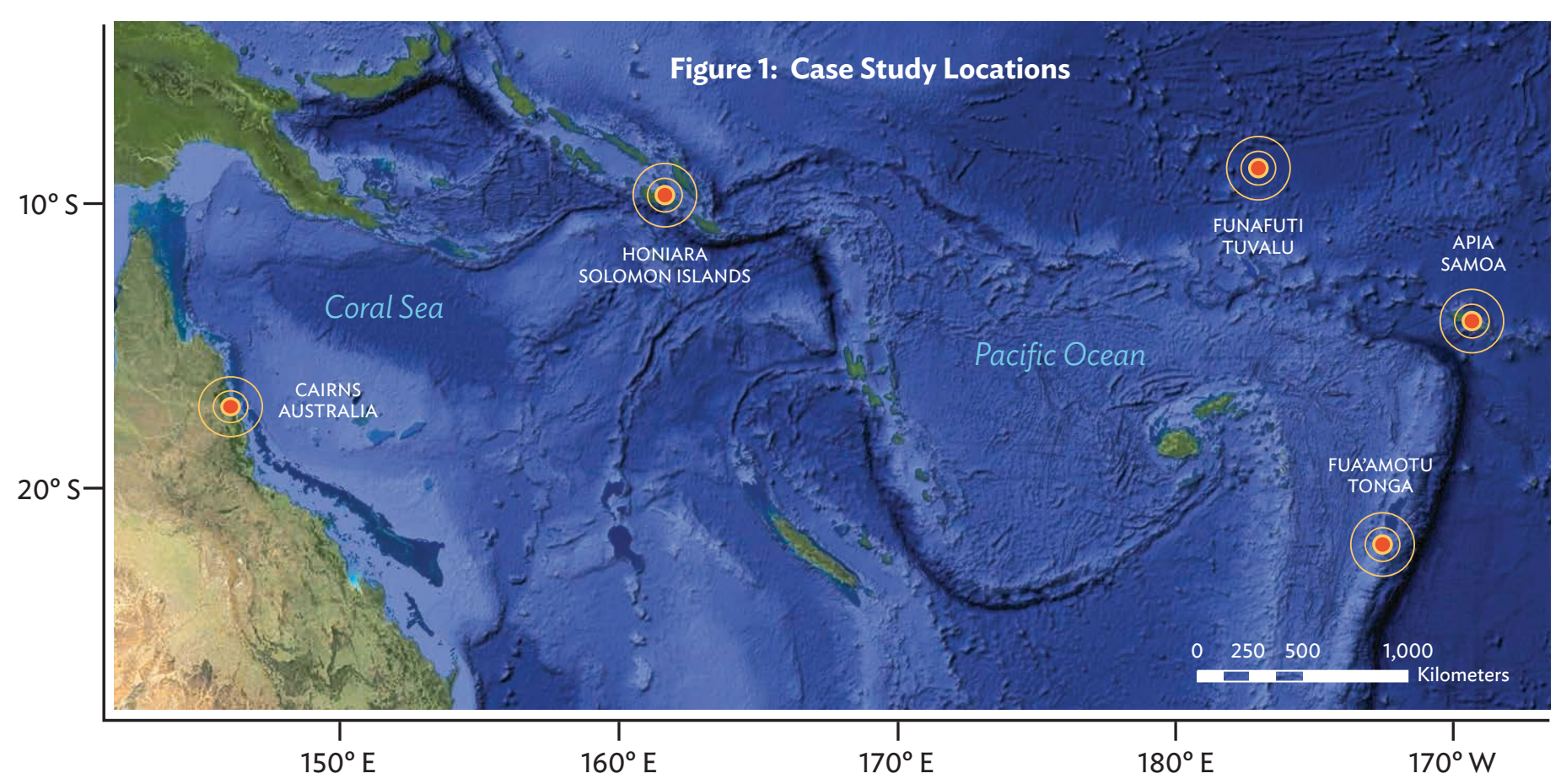

Source: Authors. 


\section{How has extreme daily rainfall intensity changed in the Pacific region over the last few decades?}

Five case studies from across the Pacific were selected to investigate how extreme daily rainfall intensity in the Pacific is changing (Figure 1). These locations were chosen because they each had long-term, complete observed records of daily rainfall data (Table 1). The analysis presented in this section focuses on the years 1989-2019 (1989-2017 for Apia), as that is the period for which the five sites had most complete, high-quality daily rainfall records.

Figure 2 shows that over the 31-year period 1989-2019 the number of extreme rainfall days for Fua'amotu and Honiara increased but not much change occurred at the other three case study locations.
Figure 3 shows that over the 31-year period 1989-2019 all case study locations experienced an increasing trend in the intensity of the wettest day each year.

Figure 4 shows that over the 31-year period 1989-2019 all case study locations experienced an increasing trend in the total amount of rainfall associated with the 5 wettest days per year, and all except Funafuti showed an increasing trend for the 10 wettest days per year.

These results for the Pacific region are consistent with increases in extreme rainfall intensity reported for other parts of the world over the last few decades (e.g., Singleton and Toumi 2013; Westra et al. 2014; Guerreiro et al. 2018; Fowler et al. 2021).

\section{Table 1: Daily Rainfall Data for Each Case Study Location}

\begin{tabular}{l|c|c|c|c} 
Station Name & Latitude $\left(^{\circ}\right)$ & Longitude $\left(^{\circ}\right)$ & $\begin{array}{c}\text { Available } \\
\text { daily rainfall }\end{array}$ & Source \\
\hline Apia & -13.8507 & 188.2486 & $1923-2017$ & Samoa Meteorological Service \\
\hline Cairns & -16.9186 & 145.7781 & $1943-2020$ & Australian Bureau of Meteorology \\
\hline Fua'amotu & -21.2417 & 184.8547 & $1989-2019$ & Tonga Meteorological Service \\
\hline Funafuti & -8.5211 & 180.8038 & $1945-2019$ & Tuvalu Meteorological Service \\
\hline Honiara & -9.4456 & 159.9729 & $1980-2019$ & Solomon Islands Meteorological Service
\end{tabular}

Source: Compiled by the Asian Development Bank.

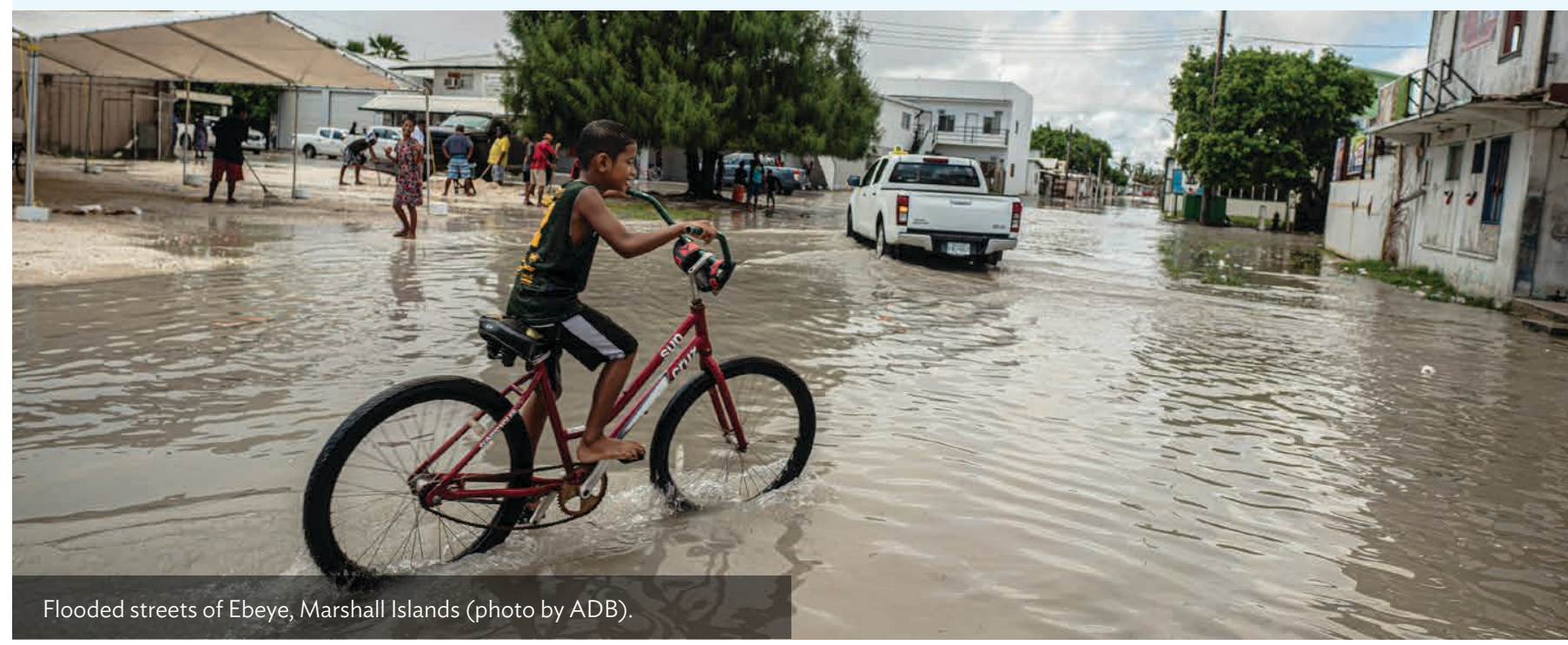


Figure 2: Extreme Rainfall Days Per Year, 1989-2019
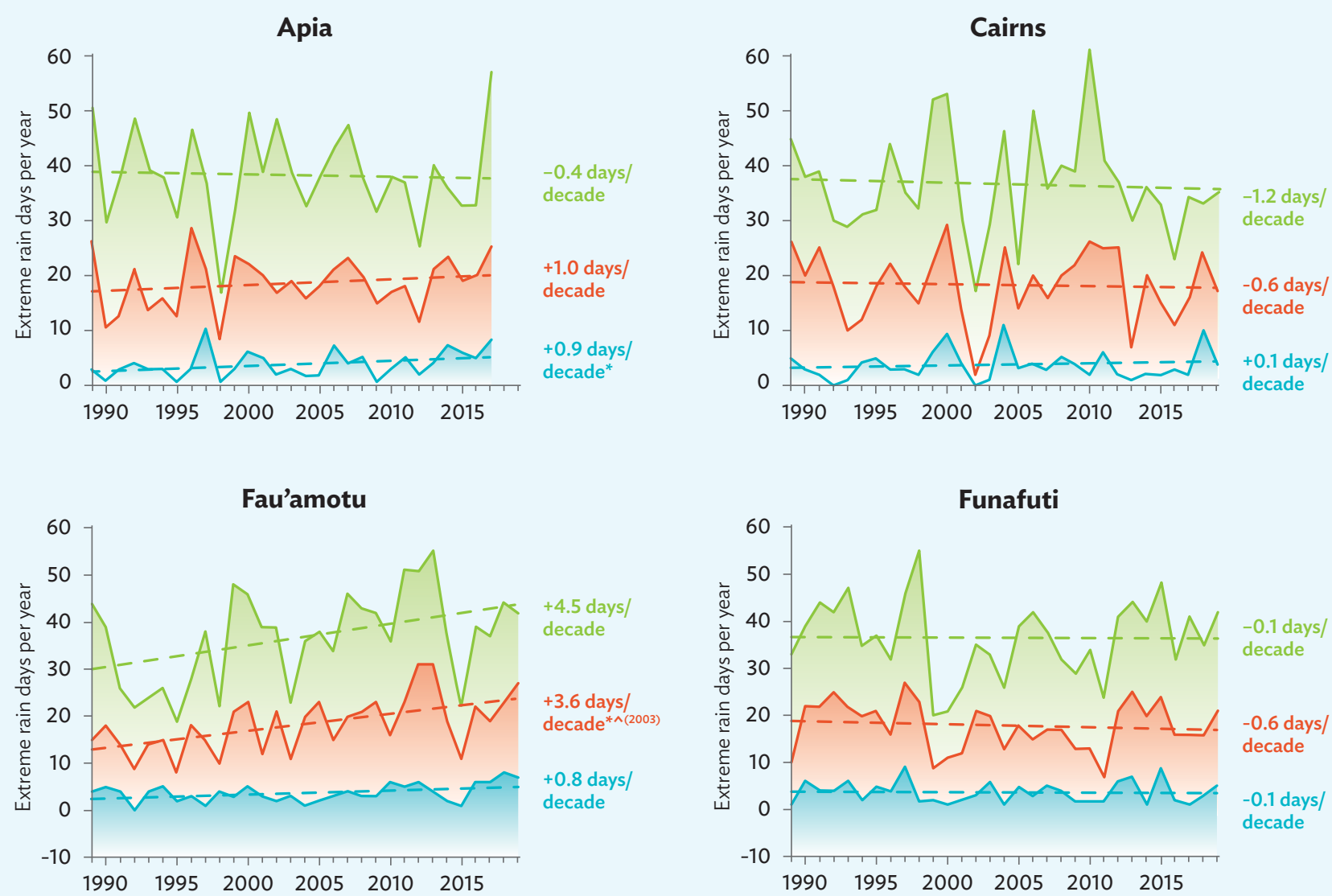

\section{Honiara}

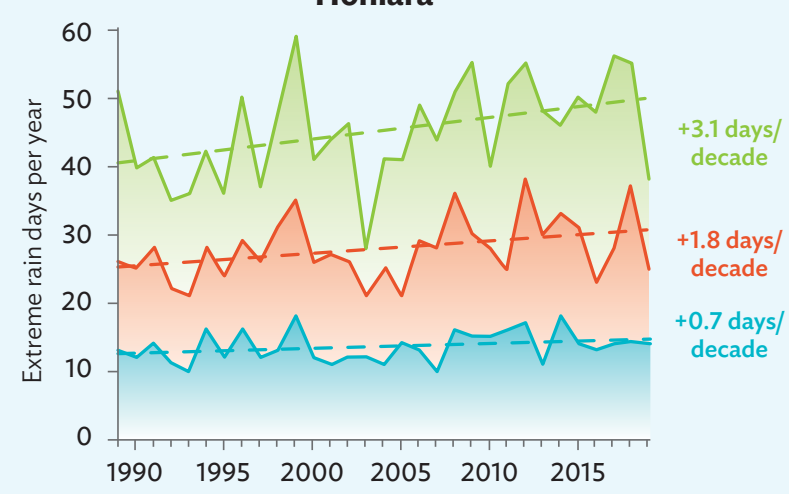

90th percentile

95th percentile

99th percentile

Notes:

1. Years applicable for Apia are 1989-2017.

2. Linear trends (dashed line) are also shown for each extreme rainfall threshold.

3. A statistically significant trend $(p$-value $<0.05)$ is indicated by $a^{*}$ (Mann-Kendall trend test) or a ^ (Pettitt test with change point year also indicated).

4. Note that the Pettitt test can give unreliable results when there are also statistically significant trends. Therefore, greater confidence is associated with change points identified when there is no statistically significant trend (i.e., a change due to non-homogenous data) (e.g., Busuioc and Storch, 1996; Mallakpour and Villarini, 2016). 


\section{Figure 3: Annual Maximum Daily Rainfall}

Apia

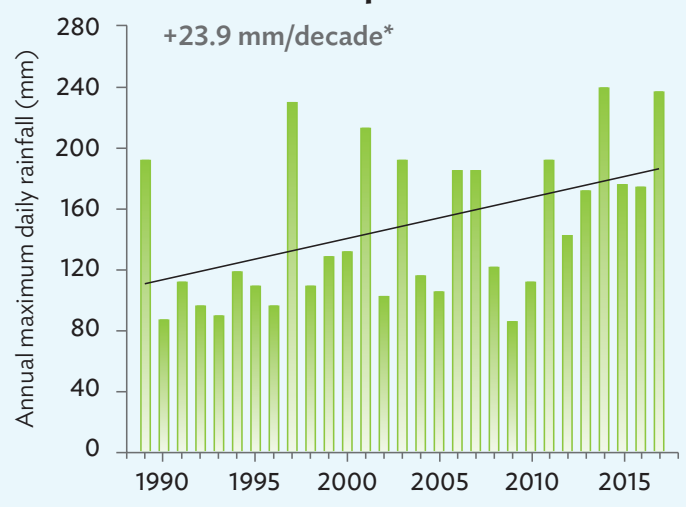

Fau'amotu

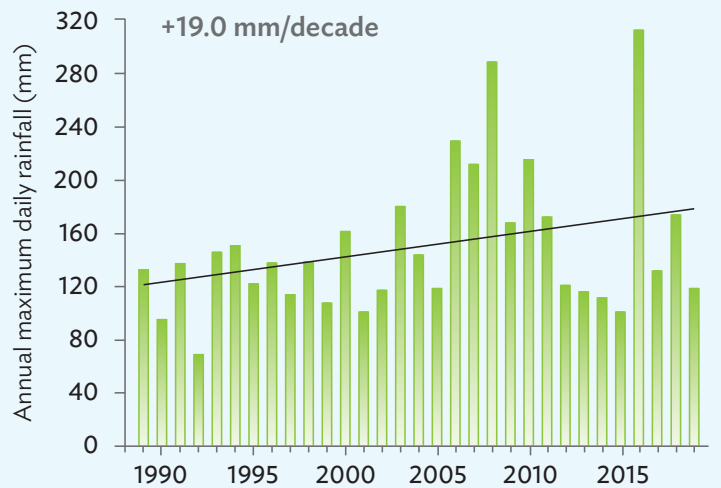

\section{Cairns}

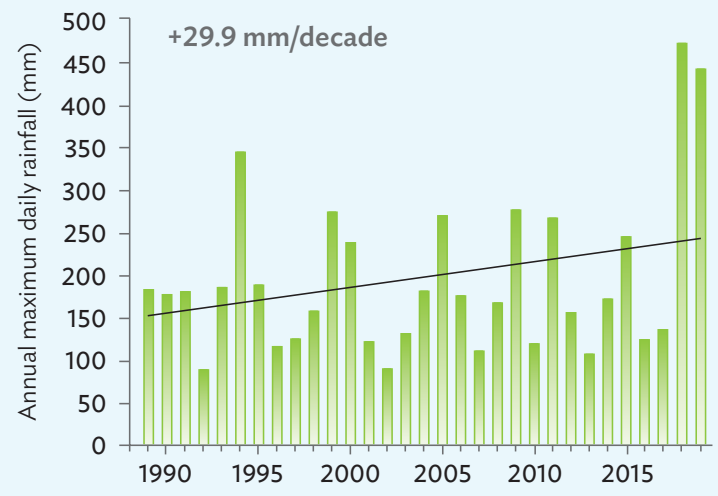

Funafuti

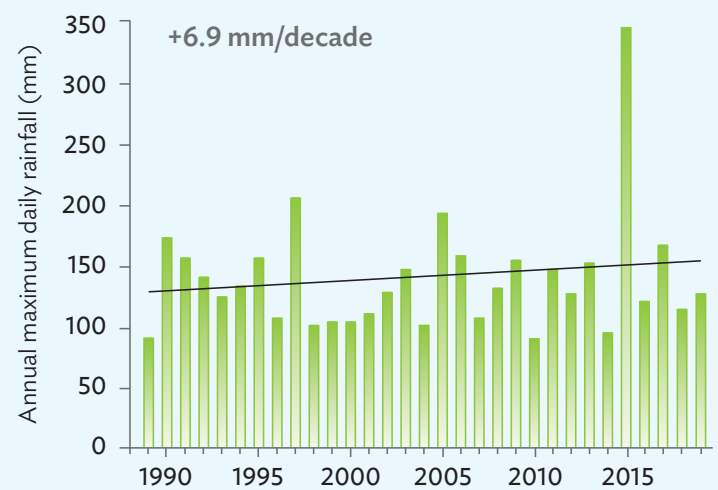

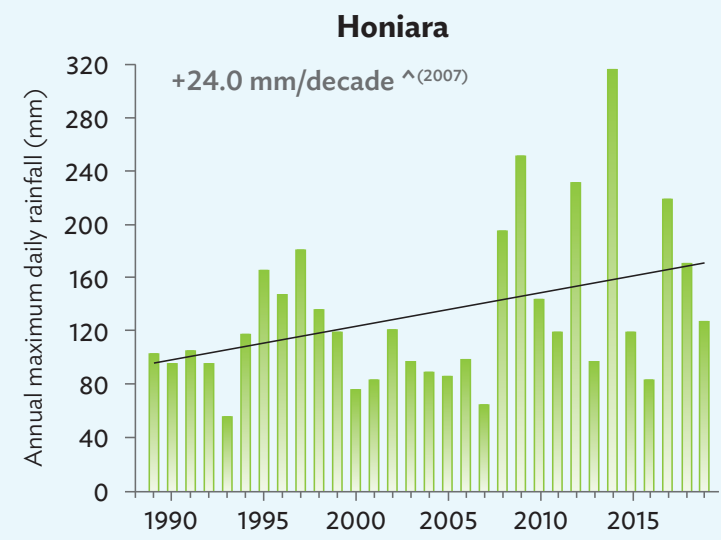

Notes:

1. Linear trends (solid line) are also shown for each location.

2. A statistically significant trend ( $p$-value $<0.05)$ is indicated by $a^{*}$ (Mann-Kendall trend test) or a ^ (Pettitt test with change point year also indicated).

3. Note that the Pettitt test can give unreliable results when there are also statistically significant trends. Therefore, greater confidence is associated with change points identified when there is no statistically significant trend (i.e., a change due to non-homogenous data) (e.g., Busuioc and Storch, 1996; Mallakpour and Villarini, 2016). 


\section{Figure 4: Total Rainfall for the Top 5 and Top 10 Wettest Days Per Year}
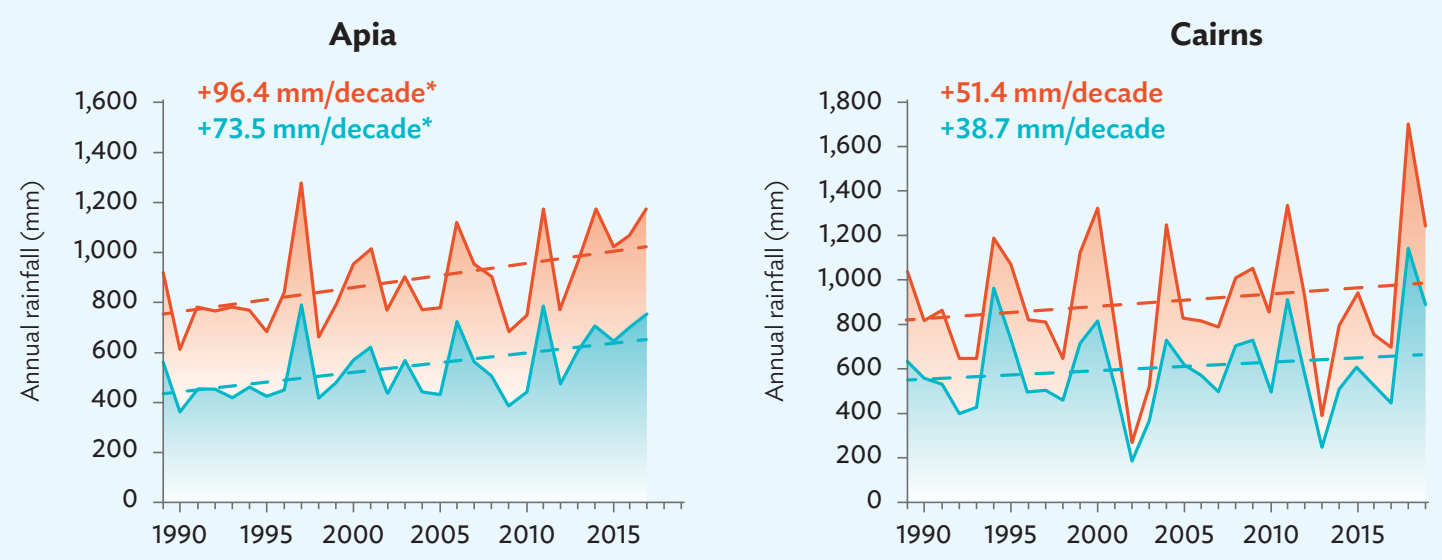

\section{Fau'amotu}
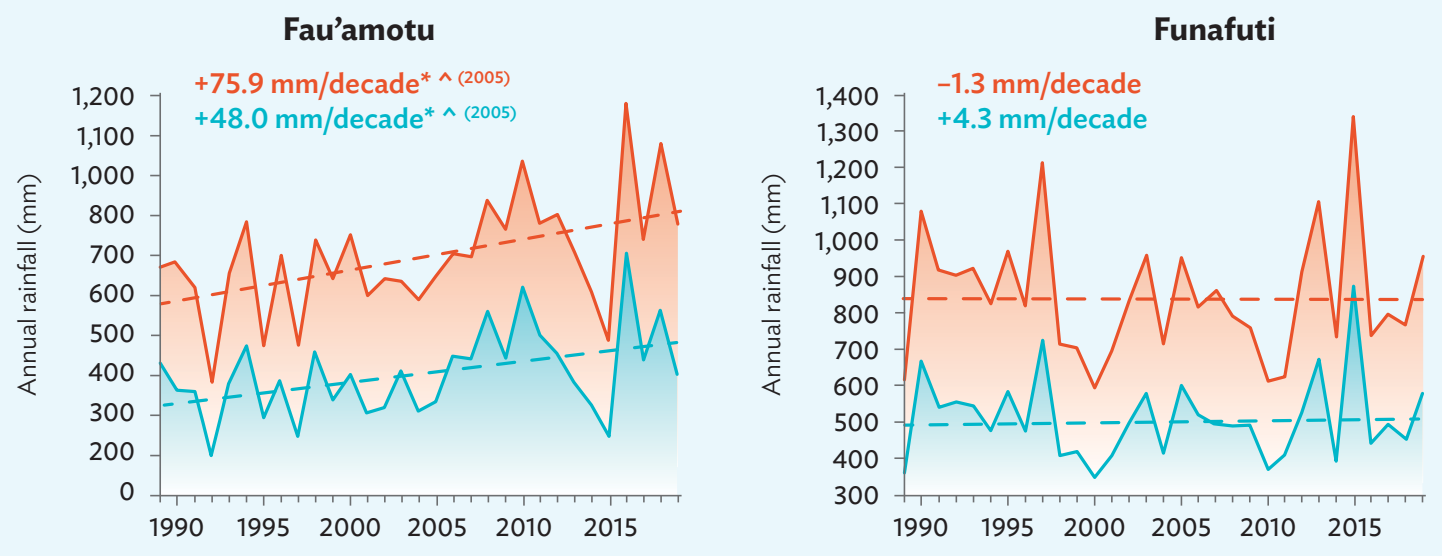

\section{Honiara}

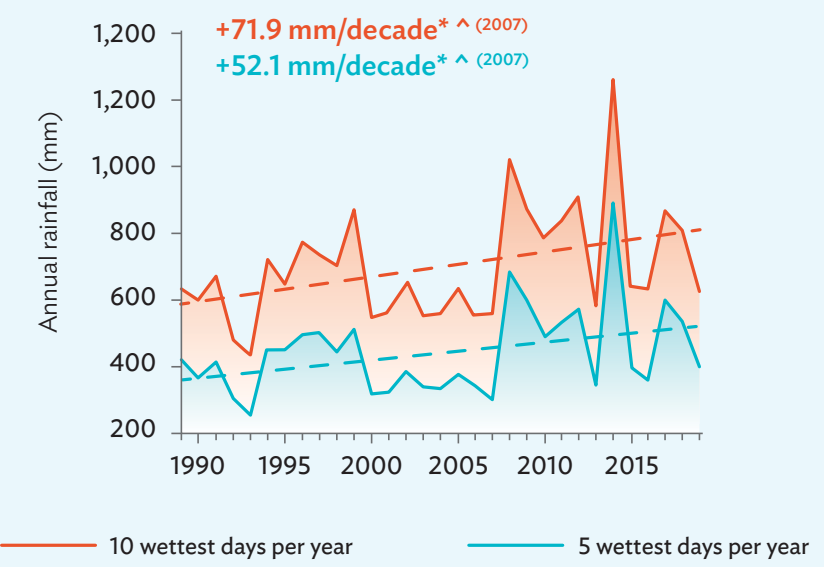

Notes:

1. Linear trends (solid line) are also shown for each location.

2. A statistically significant trend $(p$-value $<0.05)$ is indicated by $a^{*}$ (Mann-Kendall trend test) or $a^{\wedge}$ (Pettitt test with change point year also indicated).

3. Note that the Pettitt test can give unreliable results when there are also statistically significant trends. Therefore, greater confidence is associated with change points identified when there is no statistically significant trend (i.e., a change due to non-homogenous data) (e.g., Busuioc and Storch, 1996; Mallakpour and Villarini, 2016). 


\section{Are recent changes to extreme daily rainfall intensity in the Pacific in line with expectations based on the Clausius-Clapeyron rate of $5 \%-6.5 \%$ increase per ${ }^{\circ} \mathrm{C}$ of global warming?}

The analysis presented in this section focuses on Cairns and Funafuti, as these two stations have complete, high-quality daily rainfall records from at least 1960. ${ }^{1}$ Data from 1960 were required to enable comparison between two 30-year periods, in line with the World Meteorological Organization (WMO) recommendation that 30 consecutive years of data are necessary to quantify typical climate conditions for a given period (Arguez and Vose 2011).

Figure 5 shows for Cairns, and Figure 6 shows for Funafuti, the annual exceedance probability of design daily rainfall events (in millimeters) for two 30-year time periods: 1960-1989 and 1990-2019. Also shown is the change in rainfall intensity when the latter period is compared with the earlier period.
The results show a clear increase in extreme daily rainfall intensity for design daily rainfall events with a $5 \%$ annual exceedance probability or less (i.e., the most damaging rainfall events). This is expected, from the results in the previous section and based on existing literature focused elsewhere in the world (e.g., Singleton and Toumi 2013; Westra et al. 2014; Guerreiro et al. 2018; Fowler et al. 2021) but is it correct to assume that changes to extreme daily rainfall intensity in the Pacific follow the Clausius-Clapeyron rate of $5 \%-6.5 \%$ increase per ${ }^{\circ} \mathrm{C}$ of global warming.

Table 2 shows the annual average maximum daily temperature at Cairns and Funafuti for 1960-1989 and 1990-2019. This information can be used to infer the

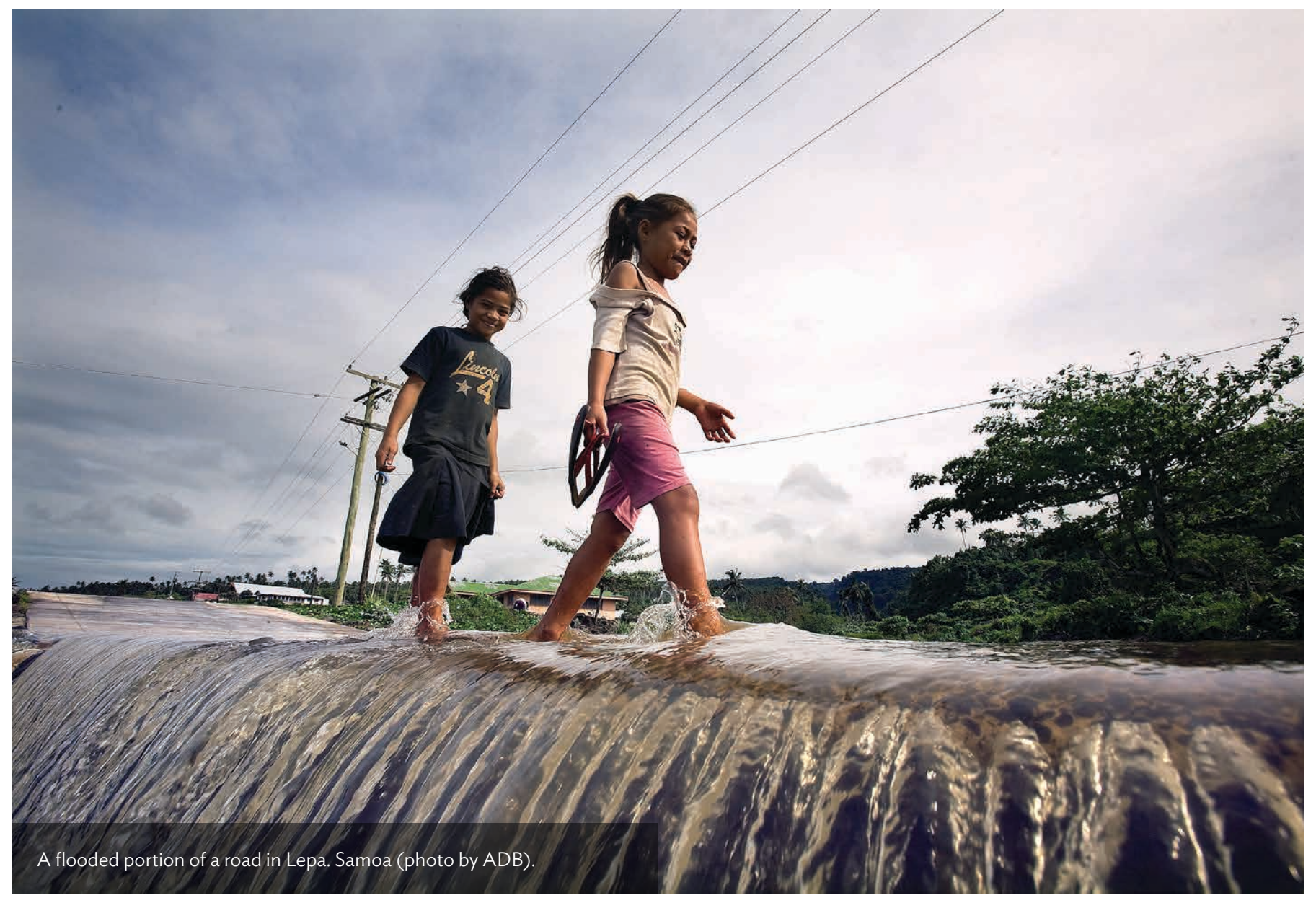

1 Apia was also considered but not used because of several periods before 1989 where the data quality is questionable. 
change in temperature between the two 30-year periods and then, based on the Clausius-Clapeyron rate, the anticipated change to extreme daily rainfall intensity.

For Cairns, the difference in annual average maximum daily temperature between the 1960-1989 and the 1990-2019 periods was $0.5^{\circ} \mathrm{C}$. Using the Clausius-Clapeyron rate, this corresponds to an anticipated $2.5 \%-3.2 \%$ increase in extreme daily rainfall intensity.

For Funafuti, the change in annual average maximum daily temperature between the 1960-1989 and the 1990-2019 periods was $0.3^{\circ} \mathrm{C}$. Using the Clausius-Clapeyron rate, this corresponds to an anticipated $1.5 \%-1.9 \%$ increase in extreme daily rainfall intensity.
For design daily rainfall events with a $5 \%$ annual exceedance probability or less (i.e., the most damaging rainfall events), the anticipated changes to extreme daily rainfall intensity calculated based on the Clausius-Clapeyron rate is significantly lower than the observed changes shown in Figure 5 and Figure 6.

These results suggest that (i) Super-Clausius-Clapeyron (Super-CC) scaling is already occurring at these sites and (ii) a method for applying Super-CC scaling is required to realistically quantify the impacts of climate change on extreme rainfall intensity in the Pacific region. ${ }^{2}$

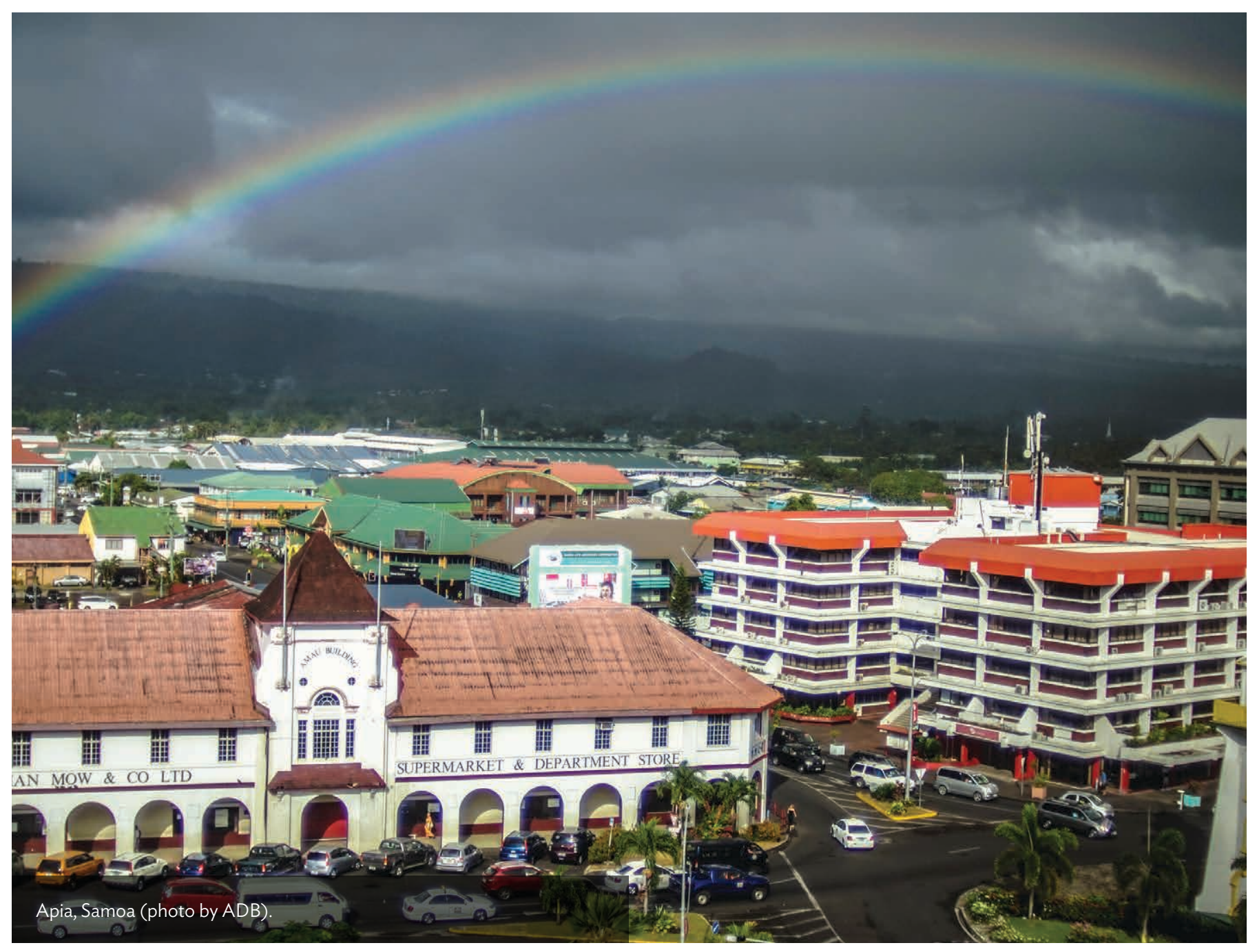

2 It is also possible that the differences between the two 30 year-periods could be attributable (at least in part) to natural climate variability. Further research is required to determine what proportion of the increase in extreme daily rainfall intensity observed since 1990 is due to natural climate variability versus Clausius-Clapeyron, or Super-CC, scaling related to anthropogenic climate change-related increased temperatures. 


\section{Figure 5: Annual Exceedance Probability of Design Daily Rainfall Events in Cairns, 1960-1989 and 1990-2019}

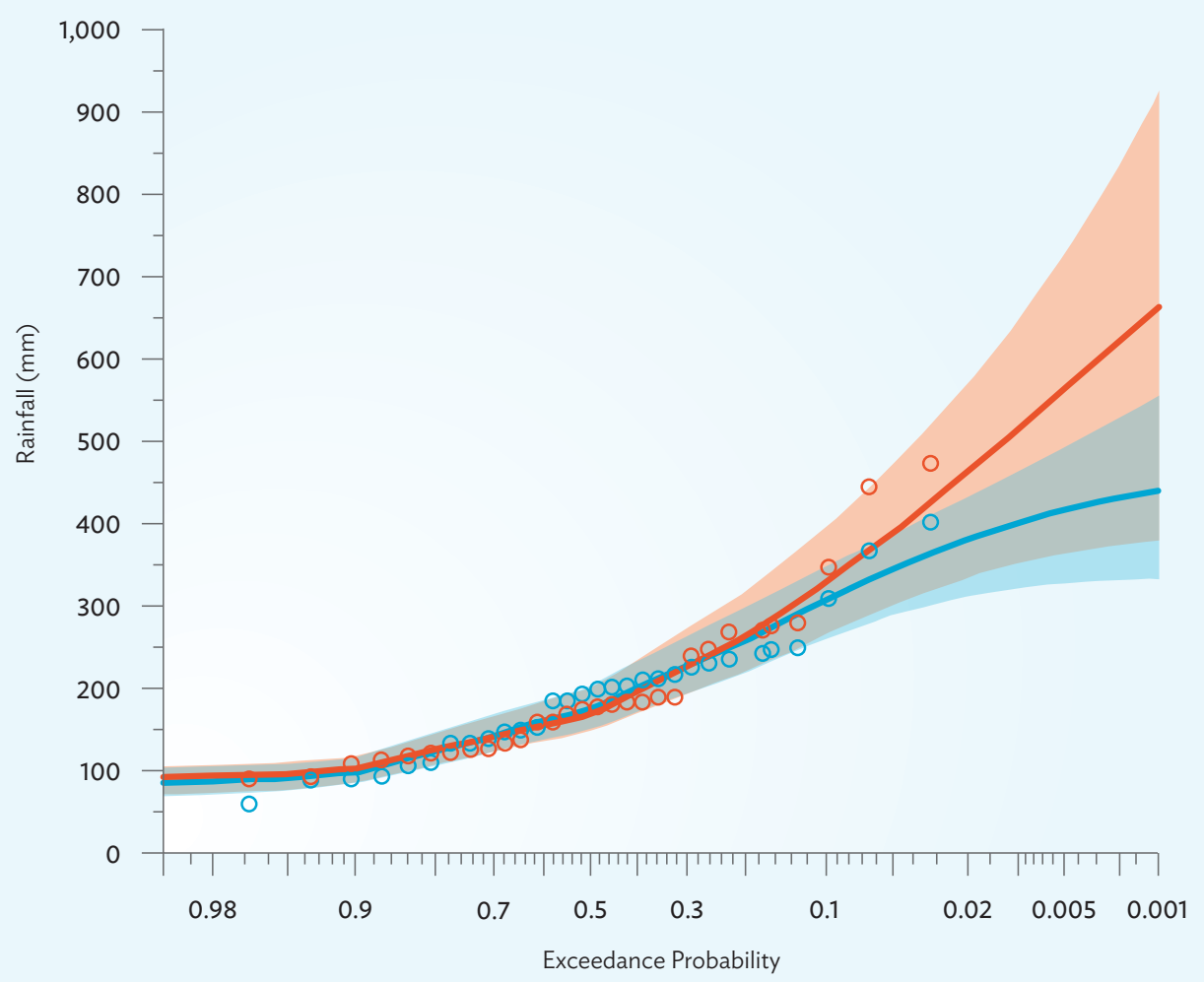

O Observations: $1960-1989$

1990-2019

O Observations: 1990-2019

\begin{tabular}{|c|c|c|c|c|}
\hline Return Period & $\begin{array}{l}\text { Annual Exceedance } \\
\text { Probability (\%) }\end{array}$ & $\begin{array}{l}\text { a. Funafuti rainfall (mm) } \\
(1960-1989)\end{array}$ & $\begin{array}{l}\text { b. Funafuti rainfall (mm) } \\
\text { (1990-2019) }\end{array}$ & $\%$ difference \\
\hline 1,000 & 0.1 & 441.3 & 663.7 & 50.4 \\
\hline 500 & 0.2 & 432.8 & 622.9 & 43.9 \\
\hline 200 & 0.5 & 417.5 & 564.4 & 35.2 \\
\hline 100 & 1.0 & 401.9 & 516.3 & 28.5 \\
\hline 50 & 2.0 & 381.6 & 464.6 & 21.8 \\
\hline 20 & 5.0 & 345.3 & 390.3 & 13.0 \\
\hline 10 & 10.0 & 308.3 & 329.2 & 6.8 \\
\hline 5 & 20.0 & 260.2 & 263.5 & 1.3 \\
\hline 0 & 50.0 & 174.1 & 169.1 & -2.9 \\
\hline
\end{tabular}

Notes:

1. Shaded area in the top plot represents $95 \%$ confidence intervals and the curves are fitted using a Generalized Pareto Distribution. It is important to note that the optimal extreme rainfall distribution is site dependent. Twenty distributions were assessed (Beta, 4 Parameter Beta, Empirical, Exponential, Gamma, Generalized Extreme Value, Generalized Logistic, Generalized Pareto, Gumbel, Logistic, Normal, Pearson III, Uniform, Triangular, Log-Logistic, Ln-Normal, Log10-Normal, Log-Pearson III, Shifted Exponential, Shifted Gamma) and the Kolmogorov-Smirnov test statistic identified the Generalized Pareto distribution as the best fitting distribution for this location.

2. Percentage (\%) change in the bottom table is calculated as 1990-2019 relative to the 1960-1989 value for each return period. Events rarer than $5 \%$ annual exceedance probability (indicated by italics in the bottom table) are included for illustrative or indicative purposes but cannot be confidently estimated from a 30-year record (e.g., Hu et al., 2020).

Source: Compiled by the Asian Development Bank. 


\section{Figure 6: Annual Exceedance Probability of Design Daily Rainfall Events in Funafuti,} 1960-1989 and 1990-2019

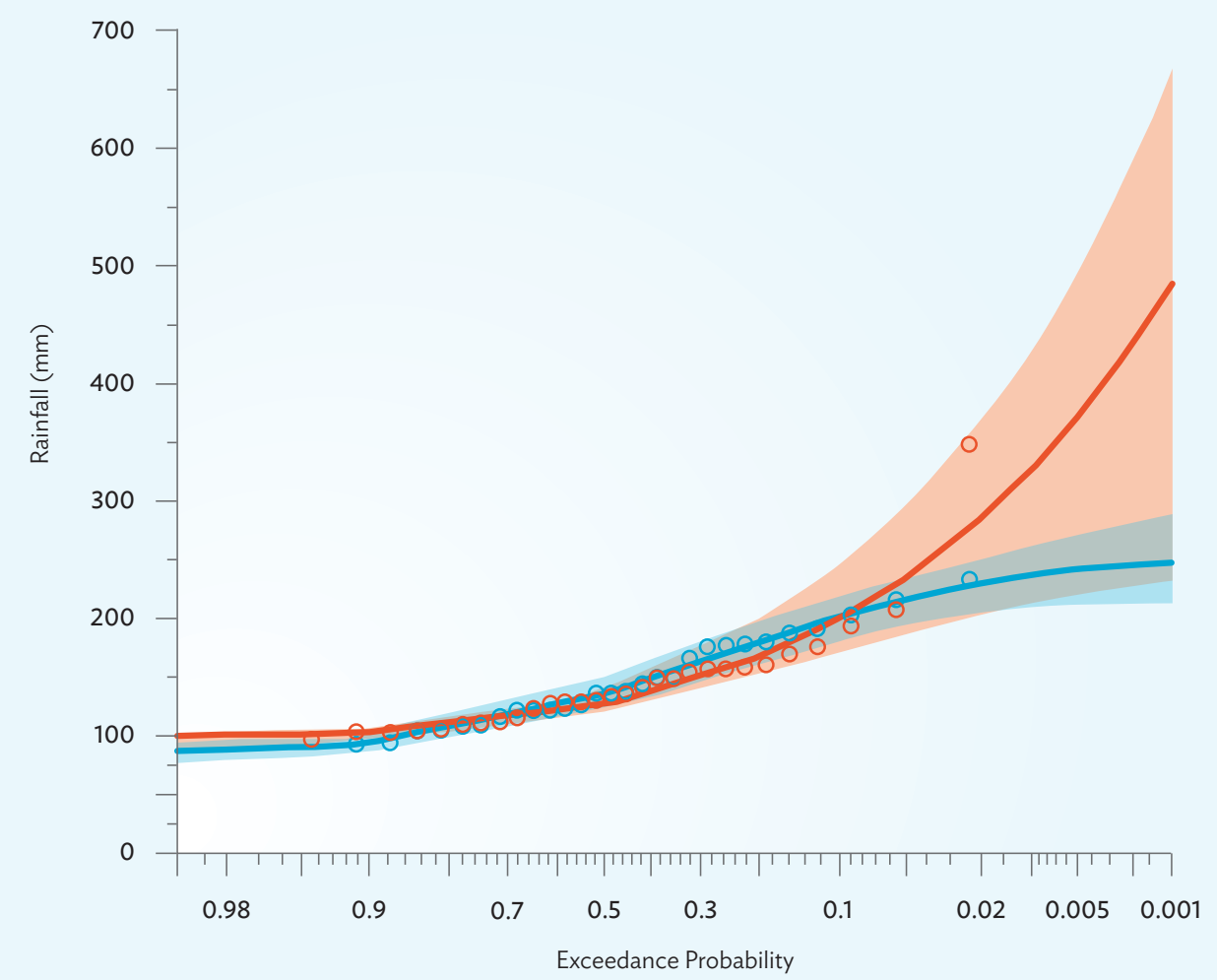

1960-1989

O Observations: $1960-1989$

1990-2019

O Observations: 1990-2019

\begin{tabular}{c|c|c|c|c} 
Return Period & $\begin{array}{c}\text { Annual Exceedance } \\
\text { Probability (\%) }\end{array}$ & $\begin{array}{c}\text { a. Funafuti rainfall (mm) } \\
(1960-1989)\end{array}$ & $\begin{array}{c}\text { b. Funafuti rainfall (mm) } \\
(1990-2019)\end{array}$ & 9 difference \\
\hline 1,000 & 0.1 & 247.5 & 485.0 & 76.0 \\
\hline 500 & 0.2 & 245.5 & 433.5 & 53.6 \\
\hline 200 & 0.5 & 241.4 & 370.7 & 38.0 \\
\hline 100 & 1.0 & 236.8 & 326.7 & 24.0 \\
\hline 50 & 2.0 & 230.2 & 285.5 & 8.5 \\
\hline 20 & 5.0 & 216.8 & 235.2 & -0.8 \\
\hline 10 & 10.0 & 201.6 & 200.0 & -7.1 \\
\hline 5 & 20.0 & 179.8 & 167.1 & -6.6 \\
\hline
\end{tabular}

Notes:

1. Shaded area in the top plot represents $95 \%$ confidence intervals and the curves are fitted using a Generalized Pareto Distribution. It is important to note that the optimal extreme rainfall distribution is site dependent. Twenty distributions were assessed (Beta, 4 Parameter Beta, Empirical, Exponential, Gamma, Generalized Extreme Value, Generalized Logistic, Generalized Pareto, Gumbel, Logistic, Normal, Pearson III, Uniform, Triangular, Log-Logistic, Ln-Normal, Log10-Normal, Log-Pearson III, Shifted Exponential, Shifted Gamma) and the Kolmogorov-Smirnov test statistic identified the Generalized Pareto distribution as the best fitting distribution for this location.

2. Percentage (\%) change in the bottom table is calculated as 1990-2019 relative to the 1960-1989 value for each return period. Events rarer than $5 \%$ annual exceedance probability (indicated by italics in the bottom table) are included for illustrative or indicative purposes but cannot be confidently estimated from a 30-year record (e.g., Hu et al., 2020).

Source: Compiled by the Asian Development Bank. 


\section{Table 2: Annual Average Maximum Daily Temperature $\left({ }^{\circ} \mathrm{C}\right)$ at Cairns and Funafuti, 1960-1989 and 1990-2019}

a. $1960-1989\left({ }^{\circ} \mathrm{C}\right)$

b. $1990-2019\left({ }^{\circ} \mathrm{C}\right)$

Difference $(b-a)\left({ }^{\circ} \mathrm{C}\right)$

\begin{tabular}{|c|c|c|c|}
\hline $\begin{array}{l}\text { Average maximum daily } \\
\text { temperature at Cairns }\end{array}$ & 28.9 & 29.4 & 0.5 \\
\hline $\begin{array}{l}\text { Average maximum daily } \\
\text { temperature at Funafuti }\end{array}$ & 29.4 & 29.7 & 0.3 \\
\hline
\end{tabular}

\section{Guidance on quantifying future changes to extreme daily rainfall intensity in the Pacific region}

Based on the small number of locations analyzed here, observed data suggests that (i) increases to extreme daily rainfall intensity have already occurred in parts of the Pacific region and (ii) these increases are beyond those expected from the widely used Clausius-Clapeyron rate of 5\%-6.5\% increase per ${ }^{\circ} \mathrm{C}$ of warming. Therefore, when conducting feasibility studies, climate risk and adaptation assessments, and infrastructure design in the Pacific, the following method should be used to apply Super-CC scaling in order to realistically quantify the impacts of climate change on extreme daily rainfall intensity.

1. Determine the initial scaling factor (SF) based on Guerreiro et al. (2018):

$$
\mathrm{SF}=1+(\Delta \mathrm{T} \times 0.065)
$$

$\Delta \mathrm{T}$ is the projected change in annual average maximum daily temperature.

$\Delta \mathrm{T}$ is calculated using the upper bound (97.5th percentile) of the full climate model ensemble for annual maximum daily temperatures at the location of interest for future time period compared with a 1980-1999 baseline.
In this example we used Coupled Model Intercomparison Project Phase 5 (CMIP5, https://www.wcrp-climate.org/wgcm-cmip/ wgcm-cmip5) maximum daily temperature change values for the Pacific that were obtained from Pacific Climate Futures (https://www. pacificclimatefutures.net/en/). While CMIP6 has been completed, downscaling for the Pacific has not yet been done. When CMIP 6 Pacific downscaled data is available (ca 2023) it should be used in preference to CMIP5.

2. Existing literature suggests that for tropical regions (north of $23^{\circ} \mathrm{S}$ and south of $23^{\circ} \mathrm{N}$ ) anthropogenic climate change-induced changes to extreme daily and sub-daily rainfall are 1.5-3 times greater than changes expected based on the Clausius-Clapeyron rate of $5 \%-6.5 \%$ increase per ${ }^{\circ} \mathrm{C}$ of global warming (e.g., Singleton and Toumi 2013; Westra et al. 2014; Guerreiro et al. 2018; Fowler et al. 2021). Short-duration (hourly and sub-hourly) rainfall intensities scale at higher rates (i.e., up to 3 times CC) than daily (i.e., 1.5 times (C). Therefore, to apply Super-CC scaling to daily rainfall extremes, the percentage increase indicated by the SF is multiplied by $1.5^{3}$ and rounded up to the nearest $5 \%$,

3 A multiplier of 1.5 (i.e., the lower bound of the Super-CC scaling range) is used because the focus here is on daily rainfall extremes. For short-duration, sub-daily rainfall extremes (i.e., hourly or sub-hourly) a multiplier greater than two is recommended. 
resulting in a new Super-CC scaling factor $\left(\mathrm{SF}_{\text {Super-CC }}\right)$. For example, a $\Delta \mathrm{T}$ of $4^{\circ} \mathrm{C}$ results in a $\mathrm{SF}$ of 1.26 (i.e., a $26 \%$ increase). Multiplying by 1.5 to account for Super-CC scaling then rounding up to the nearest $5 \%$ gives $40 \%$, resulting in a $\mathrm{SF}_{\text {Super-CC }}$ of 1.4 .
3. Projected (i.e., future) extreme daily rainfall intensity is then determined by multiplying the current extreme daily rainfall intensity by the $\mathrm{SF}_{\text {Super-cc. }}$. For example, if the current $1 \%$ annual exceedance probability daily rainfall event is $400 \mathrm{~mm}$ and the $\mathrm{SF}_{\text {Super-cc }}$ is 1.4 (as per the example in the previous step) then the projected future $1 \%$ annual exceedance probability daily rainfall event is $560 \mathrm{~mm}$, after accounting for Super-CC scaling.

\section{References}

Arguez, A., and R. S. Vose. 2011. "The Definition of the Standard WMO Climate Normal: The Key to Deriving Alternative Climate Normals." Bulletin of the American Meteorological Society 92 (6):699-704. https://doi.org/10.1175/2010bams2955.1.

Ball, J., M. Babister, R. Nathan, W. Weeks, E. Weinmann, M. Retallick, and I. Testoni, eds. 2019. Australian Rainfall and Runoff: A Guide to Flood Estimation. http://www.arr-software.org/pdfs/ARR_190514_Book1.pdf: Commonwealth of Australia (Geoscience Australia).

Busuioc, A., and H. Storch. 1996. "Changes in the winter precipitation in Romania and its relation to the large-scale circulation." Tellus A 48:538-552. https://doi.org/10.1034/J.1600-0870.1996.T01-3-00004.X.

Fowler, H. J., H. Ali, R. P. Allan, N. Ban, R. Barbero, P. Berg, S. Blenkinsop, N-S. Cabi, S. Chan, M. Dale, R. J. H. Dunn, M. Ekström, J. P. Evans, G. Fosser, B. Golding, S. B. Guerreiro, G. C. Hegerl, A. Kahraman, E. J. Kendon, G. Lenderink, E. Lewis, X-F. Li, P. A. O’Gorman, H. G. Orr, K. L. Peat, A. F. Prein, D. Pritchard, C. Schär, A. Sharma, P. A. Stott, R. Villalobos-Herrera, G. Villarini, C. Wasko, M. F. Wehner, S. Westra, and A. Whitford. 2021. "Towards advancing scientific knowledge of climate change impacts on short-duration rainfall extremes." Philosophical Transactions of the Royal Society A: Mathematical, Physical and Engineering Sciences 379 (2195):20190542. https://doi.org/10.1098/rsta.2019.0542.

Guerreiro, S. B., H. J. Fowler, R. Barbero, S. Westra, G. Lenderink, S. Blenkinsop, E. Lewis, and X-F. Li. 2018. "Detection of continental-scale intensification of hourly rainfall extremes." Nature Climate Change 8 (9):803-807. https://doi.org/10.1038/s41558-018-0245-3.

Hu, L., E. I. Nikolopoulos, F. Marra, and E. N. Anagnostou. 2020. "Sensitivity of flood frequency analysis to data record, statistical model, and parameter estimation methods: An evaluation over the contiguous United States." Journal of Flood Risk Management 13 (1):e12580. https://doi.org/10.1111/jfr3.12580.

Ivancic, T. J., and S. B. Shaw. 2016. "A U.S.-based analysis of the ability of the Clausius-Clapeyron relationship to explain changes in extreme rainfall with changing temperature.” Journal of Geophysical Research: Atmospheres 121 (7):3066-3078. https://doi.org/10.1002/2015JD024288.

Kalnay, E., M. Kanamitsu, R. Kistler, W. Collins, D. Deaven, L. Gandin, M. Iredell, S. Saha, G. White, J. Woollen, Y. Zhu, M. Chelliah, W. Ebisuzaki, W. Higgins, J. Janowiak, K. C. Mo, C. Ropelewski, J. Wang, A. Leetmaa, R. Reynolds, R. Jenne, and D. Joseph. 1996. "The NCEP/NCAR 40-Year Reanalysis Project." Bulletin of the American Meteorological Society 77 (3):437-472. https://doi.org/10.1175/1520-0477(1996)077<0437:Tnyrp>2.0.Co;2.

Lewis, E., H. J. Fowler, L. V. Alexander, R. J. H. Dunn, F. McClean, R. Barbero, S. B. Guerreiro, X-F. Li, and S. Blenkinsop. 2019. “GSDR: A Global Sub-Daily Rainfall Dataset.” Journal of Climate 32 (15):4715-4729. https://doi.org/10.1175/jcli-d-18-0143.1.

Li, X-F., S. Blenkinsop, R. Barbero, J. Yu, E. Lewis, G. Lenderink, S. B. Guerreiro, S. Chan, Y. Li, H. Ali, R. Villalobos Herrera, E. J. Kendon, and H. J. Fowler. 2020. "Global distribution of the intensity and frequency of hourly precipitation and their responses to ENSO." Climate Dynamics 54 (11):4823-4839. https://doi.org/10.1007/s00382-020-05258-7.

Mallakpour, I., and G. Villarini. 2016. "A simulation study to examine the sensitivity of the Pettitt test to detect abrupt changes in mean." Hydrological Sciences Journal 61 (2):245-254. https://doi.org/10.1080/02626667.2015.1008482.

Singleton, A., and R. Toumi. 2013. "Super-Clausius-Clapeyron scaling of rainfall in a model squall line." Quarterly Journal of the Royal Meteorological Society 139 (671):334-339. https://doi.org/10.1002/qj.1919.

Westra, S., H. J. Fowler, J. P. Evans, L. V. Alexander, P. Berg, F. Johnson, E. J. Kendon, G. Lenderink, and N. M. Roberts. 2014. “Future changes to the intensity and frequency of short-duration extreme rainfall." Reviews of Geophysics 52 (3):522-555.

https://doi.org/10.1002/2014RG000464. 